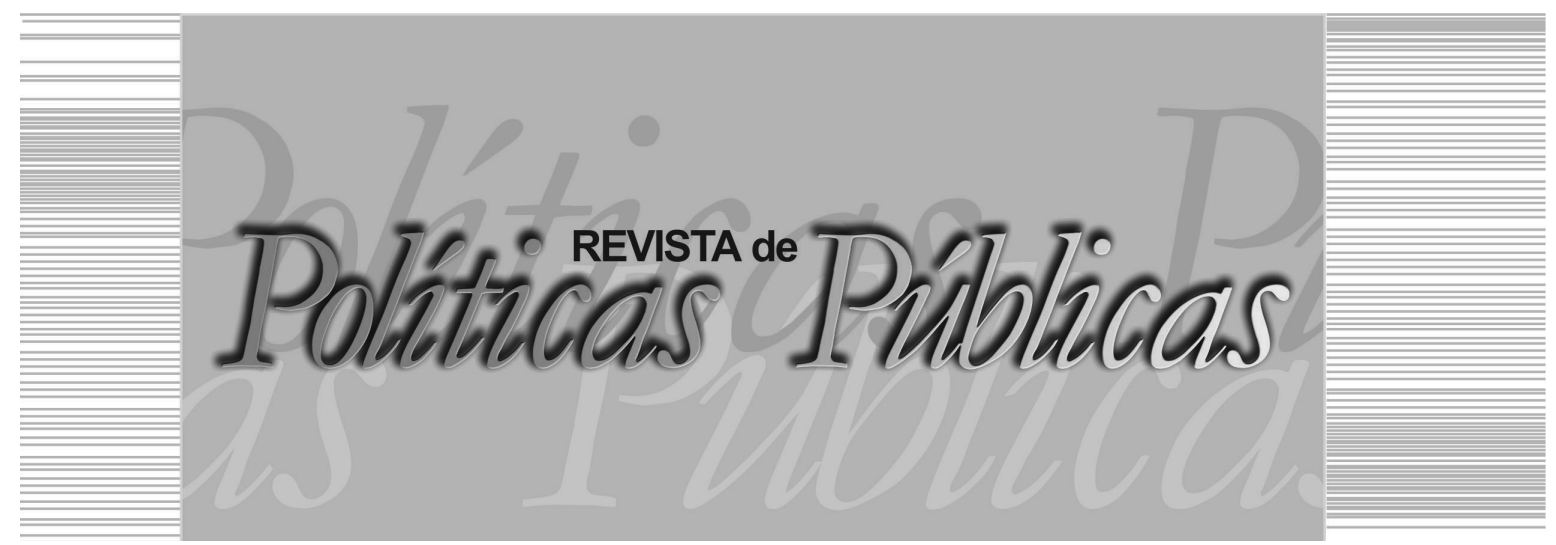

\title{
CONSTRUÇÃO DE POLITICAS PARA MELHORIA DO PROCESSO DE INTERNACIONALIZAÇÃO DA ARQUITETURA NO BRASIL: caso Apex-Brasil
}

\author{
Caio Giusti Bianchi ${ }^{1}$ \\ Escola Superior de Propaganda e Marketing (ESPM) \\ Júlio César Bastos de Figueiredo ${ }^{2}$ \\ Escola Superior de Propaganda e Marketing (ESPM)
}

\section{Resumo}

O setor de arquitetura, uma das principais indústrias criativas no Brasil, conta com características e comportamentos peculiares ao seu contexto. Com base em tais aspectos, o objetivo deste trabalho é apresentar um conjunto de propostas de políticas para melhoria do processo de internacionalização de empresas de arquitetura no Brasil. Para alcançar tal objetivo, as teorias de Modos de Entrada e Ambiente Institucional foram abordadas e aplicadas a uma pesquisa qualitativa baseada em estudo de casos múltiplos. As propostas são construídas a partir da análise de conteúdo de uma série de entrevistas feitas com diversas empresas do setor e responsáveis pelo projeto Built by Brazil da Apex-Brasil. O conjunto de propostas pode ser dividido em três abordagens: i) Desenvolvimento Interno; ii) Competitividade Internacional; e iii) Promoção de Imagem. Palavras-chave: Gestão internacional, políticas públicas, internacionalização de empresas, ambiente institucional, arquitetura.

Bacharel em Relações Internacionais, Doutorando em Inovação Internacional pelo Programa de Mestrado e Doutorado em Gestão Internacional (PMDGI) da Escola Superior de Propaganda e Marketing (ESPM). E-mail: caio.bianchi@espm.br / Escola Superior de Propaganda e Marketing - ESPM: Rua Dr. Álvaro Alvim, 123 - Vila Mariana, São Paulo SP. CEP: 04018-010

2 Bacharel em Física, Doutor em Física Nuclear pela Universidade de São Paulo (USP), Professor do PMDGI da ESPM. E-mail: jfigueiredo@espm.br 
Caio Giusti Bianchi | Júlio César Bastos de Figueiredo

\title{
POLICIES-MAKING FOR THE IMPROVEMENT OF ARCHITECTURE INTERNATIONALIZATION PROCESS IN BRAZIL: Apex-Brasil case
}

\begin{abstract}
The architecture industry, one of the most important creative industries in Brazil, has specific characteristics and behavior according to its environment. Due to such aspects, the aim of this paper is to present a set of policies proposals in order to improve Brazilian architecture companies' internationalization process. In order to achieve such goal, the Entry Modes and Institutional Environment theories were discussed and applied in a qualitative research based on multiple case studies. The proposals are derived from content analysis of a set of interviews done with several companies from the industry and with the responsible of Built by Brazil project from Apex-Brasil. The set of proposals are divided into three approaches: i) Internal Development; ii) International Competitiveness; and iii) Image Promotion.

Key words: International business, public policies, companies internationalization, institutional environment, architecture.
\end{abstract}

\section{INTRODUÇÃO}

Os setores econômicos de uma região possuem processo decisório, ações e resultados balizados de acordo com o contexto institucional em que se encontram. Dada a relevância de alguns setores, como o caso da Arquitetura no Brasil e suas áreas relacionadas, exportando no ano de 2012 o montante de 1.3 trilhões de dólares (UNITED NATIONS CONFERENCE ON TRADE AND DEVELOPMENT, 2010), é imperativa a análise de comportamento do setor e suas expectativas em relação a auxílios governamentais de internacionalização, representados pelo projeto Built by Brazil.

A execução de um projeto governamental de auxílio à internacionalização envolve aspectos relevantes sobre a capacitação dos agentes envolvidos, compreensão dos fluxos financeiros mundiais, peculiaridades do processo de internacionalização e principalmente as expectativas e receios dos agentes, minimizando assim as incertezas e riscos da internacionalização.

A justificativa da pesquisa foi construída a partir de diferentes fatores: i) a relevância da arquitetura para o desenvolvimento de negócios no Brasil, principalmente seu volume de exportação; ii) o pioneirismo da Agência Brasileira de Promoção de Exportações e Investimentos (Apex-Brasil) em executar um projeto que seja volta- 
CONSTRUÇÃO DE POLIITICAS PARA MELHORIA DO PROCESSO DE

INTERNACIONALIZAÇÃO DA ARQUITETURA NO BRASIL: caso Apex-Brasil

do exclusivamente para o setor de arquitetura; e iii) a importância do setor para o desenvolvimento econômico nacional e de promoção da imagem do país.

Com as motivações em mente, a presente pesquisa tem por objetivo apresentar um conjunto de propostas de políticas para a melhoria do processo de internacionalização de empresas de arquitetura no Brasil.

A metodologia adotada foi qualitativa com estudo de casos múltiplos, com análise documental e realização de dez entrevistas em profundidade com escritórios de arquitetura relevantes no cenário econômico brasileiro e órgãos governamentais responsáveis pelo projeto. As entrevistas foram analisadas com base em categorias dedutivas e com emergência de categorias indutivas de análise, sendo consolidadas em um mapa conceitual.

Os achados da pesquisa foram analisados frente à literatura com foco no comportamento dos escritórios participantes do projeto Built by Brazil, além de uma análise comparativa entre barreiras e expectativas de escritórios ativos e inativos no projeto. Além disso, são propostas nove políticas para potencializar o processo de internacionalização dos escritórios brasileiros de arquitetura.

\section{REFERENCIAL TEÓRICO}

\subsection{Ambiente institucional}

A visão baseada em instituições aborda a lacuna existente na visão baseada na indústria e visão baseada em recursos: a ausência do foco no papel das instituições na gestão estratégica de empresas. (NARAYANAN; FAHEY, 2005; PRIEM; BUTLER, 2001). Apesar de haver divergências no que tange a definições das instituições entre autores, há um ponto de convergência a ser destacado: há necessidade de considerar as instituições na análise dos processos de tomada de decisão.

North (1990), com base na ótica econômica, define que instituições são a agregação de restrições provenientes das interações humanas. Já Scott (1995), voltado para a sociologia, as define como atividades e estruturas reguladoras, normativas e cognitivas que oferecem significado e estabilidade ao comportamento da sociedade. Além das duas definições anteriores, o relatório de 1999 do Banco 
Mundial (BM) define instituições como o conjunto formal e informal de regras e as interações dos participantes no desenvolvimento econômico. (WORLD BANK, 1999).

A principal característica que diferencia a visão institucional é o fato de que as tomadas de decisão não são vistas apenas como influenciadas pela competitividade encontrada no mercado ou por recursos disponíveis no mesmo. $\mathrm{O}$ tomador de decisão se encontra inserido em um contexto específico e particular, então a dinâmica da interação entre as instituições locais e a organização em questão influencia as escolhas estratégicas da empresa. (PENG et al., 2009).

As instituições de um país são responsáveis por exercer o papel de norteadoras do processo decisório empresarial, reduzindo a incerteza das estratégias empresariais. Tais empresas interagem com os limites estabelecidos pelas instituições a partir do momento que as utilizam para alcançar seus interesses de maneira racional e legítima. De acordo com Scott (1995), os limites estabelecidos são desenhados por três aspectos: i) a conveniência das instituições coercitivas; ii) o compromisso social das instituições normativas; e iii) os valores estabelecidos como certos (taken-for-granted basis) das instituições cognitivas.

As instituições coercitivas, definidas principalmente pelo papel do governo em uma região, são observáveis no ambiente. Porém Peng e outros (2009) afirma que, quando as instituições coercitivas de um ambiente não são sólidas o suficiente para reduzir a incerteza das tomadas de decisão, as instituições normativas e cognitivas assumem um papel importante na condução das empresas.

Então, o ambiente institucional oferece uma base para a análise da gestão estratégica do setor de arquitetura, principalmente no que tange à relevância das instituições brasileiras na internacionalização do setor. Com base no escopo da pesquisa, as instituições coercitivas são abordadas como relevantes para a compreensão do fenômeno estudado. O governo é a instituição coercitiva diretamente observada na realidade, principalmente com a Apex-Brasil e as agências de auxílio em geral.

\subsection{Modos de entrada}

Coviello e Martin (1999) afirmam que a internacionalização de serviços é abrangente e envolve diferenças entre os tipos de em- 
CONSTRUÇÃO DE POLÍTICAS PARA MELHORIA DO PROCESSO DE

INTERNACIONALIZAÇÃO DA ARQUITETURA NO BRASIL: caso Apex-Brasil

presas, sejam de hard services, sejam de soft services, (como classifica Erramilli, 1990), o que impossibilita a aplicação direta de uma teoria específica de internacionalização de empresas.

Já Johanson e Vahlne (1990) destacam que as teorias de internacionalização não são diretamente aplicáveis a empresas de serviços, fazendo-se necessária uma análise contextual da empresa para compreender se há coerência na relação entre teoria e realidade.

É possível observar divergências na literatura no que tange à classificação dos modos de entrada, sendo a classificação de Peng (2008), Root (1994) e Cavusgil, Knight e Riesenberger (2010) utilizada na pesquisa. Com base nos autores, três principais modos de entrada podem ser destacados: por exportação, contratual e por investimento direto.

A internacionalização por meio da exportação é o modo de entrada mais simples. É utilizada principalmente por empresas de pequeno porte quando seu produto final é produzido fora do país de destino e, posteriormente, é enviado a ele. A empresa que utiliza a exportação como meio de internacionalização possui vantagens como o baixo investimento e baixos riscos, mas também possui baixo controle dos seus produtos no mercado alvo. (ROOT, 1994).

A internacionalização por contrato é uma associação de longo prazo de caráter não patrimonial entre uma empresa nacional e outra empresa no mercado estrangeiro. $\mathrm{O}$ modo de entrada não é focado apenas nos bens transferidos, também envolve transferência tecnológica e recursos humanos entre as empresas. A internacionalização por contrato pode ser dividida entre três tipos: licenciamento, franquia e aliança/parceria. (TANURE; DUARTE, 2006).

Já a internacionalização por investimento direto é o nível mais avançado de comprometimento entre uma empresa nacional e o mercado alvo, pois envolve construção de propriedades, plantas ou outras espécies de unidades de produção no mercado estrangeiro. $\mathrm{O}$ investimento direto pode ser realizado através de propriedade exclusiva ou joint ventures. (GARRIDO et al., 2013).

\section{CONTEXTUALIZAÇÃO DO CASO APEX-BRASIL}

O projeto da Agência Brasileira de Promoção de Exportações e Investimentos (Apex-Brasil), nomeado Built by Brazil, tem por objetivo auxiliar na internacionalização do setor de arquitetura, sen- 
do resultado de uma parceria entre a agência e a Associação Brasileira dos Escritórios de Arquitetura (AsBEA). O projeto foi selecionado como objeto de pesquisa por ser um dos principais projetos da Apex-Brasil e por ser um alto investimento governamental em uma indústria específica e consolidada.

A Apex-Brasil é parte do Ministério do Desenvolvimento, Indústria e Comércio Exterior (MDIC) e foi fundada no ano de 2003. A agência oferece serviços e produtos com o objetivo de qualificar a exportação brasileira, promover o comércio internacional, o posicionamento brasileiro no mercado exterior e apoiar a internacionalização de empresas por meio da internacionalização de negócios e da atração de Investimentos Estrangeiros diretos.

No ano de 2015, a Apex-Brasil alcançou a marca de 13 mil empresas brasileiras sendo apoiadas, totalizando 81 setores da economia. No ano de 2011, as empresas parceiras da Apex-Brasil corresponderam a $15,46 \%$ do volume total exportado pelo Brasil para além de 200 mercados. A agência é composta por seis grupos de ação, sendo eles: moda, tecnologia e saúde, máquinas e equipamentos, economia criativa e serviços (onde a arquitetura está inserida), casa e construção, alimentos e bebidas e agronegócios. (AGÊNCIA BRASILEIRA DE PROMOÇÃO DE EXPORTAÇÕES E INVESTIMENTOS, [2014]).

O segundo agente institucional envolvido no projeto Built by Brazil é a AsBEA. Com fundação em 1973, é uma associação de classe que busca contribuir para o processo de evolução da arquitetura brasileira e sua valorização tanto no desenvolvimento urbano como na melhoria da qualidade da construção civil brasileira.

A associação possui mais de 300 escritórios parceiros no país, oferecendo participação em feiras de negócios, viagens de atualização profissional e encontros periódicos. Também promove publicações com tiragem mensal de 20 mil exemplares de um informativo, além de e eventos para integrar a indústria, seus associados e as empresas da construção civil. (ASSOCIAÇÃO BRASILEIRA DOS ESCRITÓRIOS DE ARQUITETURA, [2014]).

O projeto Built by Brazil é coordenado pela Apex-Brasil, seu agente financiador, e a AsBEA no papel de agente interlocutor e viabilizador das ações. O projeto foi iniciado no ano de 2010 e tem por objetivo construir um ambiente setorial em que haja a emergência 
CONSTRUÇÃO DE POLÍTICAS PARA MELHORIA DO PROCESSO DE

INTERNACIONALIZAÇÃO DA ARQUITETURA NO BRASIL: caso Apex-Brasil

de uma cultura exportadora entre escritórios de arquitetura por meio da visibilidade de profissionais brasileiros no exterior e por meio do fortalecimento da imagem da arquitetura brasileira ao redor do mundo (BUILT BY BRAZIL, 2014).

\subsection{O Setor de Arquitetura}

O setor de arquitetura como uma das indústrias criativas é o mais expressivo em termos quantitativos. Envolvendo as três grandes áreas, a indústria engloba 833 mil empresas, sendo 28 mil que estão concentradas no núcleo criativo. Também, entre o núcleo criativo de arquitetura, os serviços são as atividades que possuem o maior número de empresas, com nove mil.

No quesito empregabilidade, a indústria de arquitetura também fica em primeiro lugar em meio às indústrias criativas, seja no núcleo, com 230 mil trabalhadores, seja nas três grandes áreas, com 2,7 milhões de trabalhadores. A indústria também é a segunda melhor remunerada da economia criativa brasileira, com uma renda média mensal de $\mathrm{R} \$ 7.517$, enquanto a renda média mensal do trabalhador brasileiro é de R $\$ 1.733$ e a média do trabalhador da economia criativa é de R\$ 4.693. (FEDERAÇÃO DAS INDÚSTRIAS DO ESTADO DO RIO DE JANEIRO, 2012).

Em relação à distribuição geográfica de arquitetos no Brasil, $58 \%$ se encontram na região sudeste, $18 \%$ na região sul, $14 \%$ na região nordeste, $6 \%$ na região Centro-Oeste e $4 \%$ na região norte. (OLIVEIRA, 2013). O Brasil é o quarto maior exportador de serviços de arquitetura do mundo, sendo que em 2012 o setor de arquitetura, engenharia e outros serviços técnicos (ou seja, as três grandes áreas da indústria de arquitetura) exportou o montante de US\$ 8.944.835.866 e importou o montante de US\$ 4.704.010.689, ou seja, um superávit de US\$ 4.240.825.177 (UNITED NATIONS, [2014]).

Os dados referentes ao setor de arquitetura no Brasil representam a relevância do setor para a economia brasileira e o seu destaque quando inserido na economia criativa. A arquitetura se destaca entre as indústrias criativas como a mais relevante, que gera mais riqueza e que mais cresce anualmente, alcançando um crescimento mundial de $20,9 \%$ ao ano, acima da média da economia criativa. (UNITED NATIONS CONFERENCE ON TRADE AND DEVELOPMENT, 2010). 


\section{METODOLOGIA DE PESQUISA}

A pesquisa coletou dados a partir de três pontos de vista sobre o projeto Built by Brazil: escritórios ativos no projeto, escritórios inativos e os órgãos institucionais responsáveis pelo projeto. O motivo desta divisão deu-se porque a análise a partir de apenas um ponto de vista causaria viés na pesquisa. Com isso em mente, os gerentes do projeto Built by Brazil e da Apex-Brasil foram considerados na análise, além de oito escritórios de arquitetura.

Foram realizadas entrevistas semiestruturadas com oito escritórios de arquitetura relacionados ao projeto, o responsável pelo mesmo na Apex-Brasil e a gestora do projeto na AsBEA, além da análise documental do histórico e estratégia dos escritórios e dos registros governamentais. Há, então, quatro fontes de dados diferentes na pesquisa, além de duas técnicas de coleta de dados: entrevistas com oito empresas de arquitetura, entrevista com o responsável pelo projeto Built by Brazil da Apex-Brasil, entrevista com a gestora do projeto da AsBEA e documentos governamentais e empresariais. (DENZIN, 1970).

As entrevistas, gravadas e transcritas, foram analisadas de acordo com os preceitos da análise de conteúdo. Tal técnica possibilita analisar em profundidade as respostas dos entrevistados, identificando grupos de palavras que se destacam para compreensão do seu sentido latente. O objetivo da técnica é interpretar e reinterpretar as entrevistas e alcançar a compreensão dos significados do conteúdo por meio da categorização a partir de conceitos da literatura e emergentes. (KRIPPENDORFF, 1986).

\subsection{Amostra de Pesquisa}

O processo de seleção da amostra foi dividido em três fases: 1) coleta via portal online do projeto; 2) coleta via indicação pela AsBEA dos cinco escritórios mais atuantes do projeto; e 3) coleta via sistema de cadastramento interno do projeto. Os oito escritórios de arquitetura foram divididos em quatro que são ativos no Built by Brazil e quatro que se retiraram do projeto.

Na primeira fase de seleção, o website do projeto foi acessado e, por conta da ausência de atualização da lista, foram recuperados os oito primeiros escritórios a fazer parte do projeto. Dos oito escri- 
CONSTRUÇÃO DE POLÍTICAS PARA MELHORIA DO PROCESSO DE

INTERNACIONALIZAÇÃO DA ARQUITETURA NO BRASIL: caso Apex-Brasil

tórios iniciais, apenas quatro estavam operantes e foram entrevistados, sendo três ativos no projeto e um inativo.

$\mathrm{Na}$ segunda fase, a gestora do Built by Brazil foi acionada para o envio de uma lista dos escritórios ativos que demonstram interesse e assiduidade nas reuniões do projeto. Com base na lista enviada, o quarto e último escritório ativo foi selecionado com base em três critérios: experiência em projetos internacionais, expressividade de mercado e tempo de participação no projeto.

$\mathrm{Na}$ terceira fase, houve contato com a gestora do projeto para o envio da lista completa de participantes do projeto. Com base em tal lista, apenas os escritórios inativos foram filtrados (71), e foi realizado um levantamento individual de dados secundários para seleção dos três escritórios inativos a serem entrevistados. Os critérios de seleção foram replicados da segunda fase, ou seja, a experiência internacional, expressividade de mercado e tempo de participação no projeto.

Após o desenvolvimento das três fases de seleção, o Quadro 1 resume a amostra de pesquisa, englobando os escritórios de arquitetura, as instituições e sua situação frente ao projeto.

Quadro 1 - Amostra de Pesquisa

\begin{tabular}{|c|c|c|}
\hline Empresa & Cidade & Situação \\
\hline Stemmer Rodrigues Arquitetos Associados & Porto Alegre - RS & \multirow{4}{*}{ Ativo } \\
\hline Aflalo e Gasperini Arquitetos & São Paulo - SP & \\
\hline Debiagi Arquitetos Urbanistas & Porto Alegre - RS & \\
\hline Studio Arthur Casas & São Paulo - SP & \\
\hline Borelli \& Merigo Arquitetura e Urbanismo & São Paulo - SP & \multirow{4}{*}{ Inativo } \\
\hline Athiê / Wohnrath Associados & São Paulo - SP & \\
\hline Cristina Maluf Arquitetura de Iluminação & Porto Alegre - RS & \\
\hline Edo Rocha Arquitetura e Planejamento & São Paulo - SP & \\
\hline AsBEA & São Paulo - SP & \multirow{2}{*}{ Instituição } \\
\hline APEX & Brasília - DF & \\
\hline
\end{tabular}

\subsection{Categorias de Análise}

Para elaboração do roteiro de entrevistas e análise dos dados, foram levantadas cinco categorias. O objetivo das categorias de aná- 
lise é nortear as entrevistas, embasar o roteiro e posteriormente guiar a categorização na análise de conteúdo. O Quadro 2 ilustra as cinco categorias e as principais obras utilizadas para sua criação.

Quadro 2 - Categorias Dedutivas de Análise e Principais Autores

\begin{tabular}{|c|c|c|c|}
\hline BLOCO & & CATEGORIA & AUTORES \\
\hline \multirow{5}{*}{ 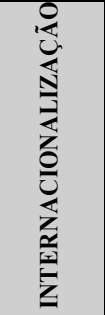 } & 1 & Barreiras & $\begin{array}{l}\text { Johanson e Vahlne (1977); Lopez e Gama (2007); Rocha } \\
\text { (2003) }\end{array}$ \\
\hline & 2 & Motivações & $\begin{array}{l}\text { Cassano et al. (2007); Coutinho et al. (2008); Oviatt e } \\
\text { McDougall (1994); Rocha et al. (2007) }\end{array}$ \\
\hline & 3 & Facilitadores & $\begin{array}{l}\text { Websites, jornais e relatórios (http://www.asbea.org.br/; } \\
\text { http://www.builtbybrazil.com.br; entre outros) }\end{array}$ \\
\hline & 4 & Estratégia Adotada & $\begin{array}{l}\text { Buckley e Casson (1998); Cyrino e Oliveira Jr. (2002); } \\
\text { Garrido (2007) }\end{array}$ \\
\hline & 5 & | Visão Empresarial & Adam Koch (2001); Doyle e Gildengil (1977); Root (1994) \\
\hline \multirow{5}{*}{ 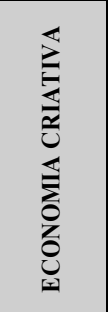 } & 1 & Força de Trabalho & $\begin{array}{l}\text { Florida (2003); Florida (2002); GCI (2011); Murteira e } \\
\text { Branquinho (1970) }\end{array}$ \\
\hline & 2 & Inovação & Achyles da Costa (2006); Albuquerque (1998); GCI (2011) \\
\hline & 3 & Diversidade & Florida (2002); Nova Scotia (2012); Bianchi e Borini (2013) \\
\hline & 4 & Criatividade & Blythe (2001); Florida (2002); Florida (2003) \\
\hline & 5 & Classe Criativa & Florida (2002); Hofstede (2010); Nicolaci-Da-Costa (2001) \\
\hline
\end{tabular}

Fonte: Elaborado pelos autores.

Foram derivadas três subcategorias dedutivas para cada categoria do Quadro 2. As subcategorias dedutivas sofreram modificações ao longo da análise de conteúdo por conta de congruências semânticas, e, ao longo da análise, emergiram subcategorias indutivas que compuseram o Quadro 3 de subcategorias de análise da pesquisa. 
CONSTRUCỸ̃ DE POLÍTICAS PARA MELHORIA DO PROCESSO DE INTERNACIONALIZAÇÃO DA ARQUITETURA NO BRASIL: caso Apex-Brasil

Quadro 3 - Categorias de Análise Dedutivas e Indutivas

\begin{tabular}{|c|c|c|}
\hline Categoria & & Subcategoria \\
\hline \multirow{7}{*}{ Barreiras } & a & Tarifárias $^{1}$ \\
\hline & \multirow{2}{*}{ b } & Não tarifárias ${ }^{2}$ \\
\hline & & Conhecimento de mercado $^{2}$ \\
\hline & c & Baixa Profissionalização ${ }^{3}$ \\
\hline & d & Imagem País - ${ }^{3}$ \\
\hline & e & Experiência - ${ }^{3}$ \\
\hline & $\mathbf{f}$ & Risco $^{3}$ \\
\hline \multirow{4}{*}{ Motivações } & a & Ambiente Int/Ext ${ }^{1}$ \\
\hline & b & Tecnologia/Inovação ${ }^{1}$ \\
\hline & c & Dirigentes ${ }^{1}$ \\
\hline & d & Status $^{3}$ \\
\hline \multirow{7}{*}{ Facilitadores } & a & Governo $^{1}$ \\
\hline & b & AsBEA $^{1}$ \\
\hline & c & Built by Brazil $^{1}$ \\
\hline & d & Expectativa $\mathrm{BBB}^{3}$ \\
\hline & e & Imagem País $+^{3}$ \\
\hline & $\mathbf{f}$ & Experiência $+^{3}$ \\
\hline & g & Cliente $^{3}$ \\
\hline \multirow{3}{*}{$\begin{array}{l}\text { Estratégia } \\
\text { Adotada }\end{array}$} & a & Exportação $^{1}$ \\
\hline & b & Contratual $^{1}$ \\
\hline & c & Investimento Direto $^{1}$ \\
\hline \multirow{4}{*}{$\begin{array}{c}\text { Visão } \\
\text { Empresarial }\end{array}$} & a & Inocente $^{1}$ \\
\hline & b & Indiferença $^{3}$ \\
\hline & \multirow[b]{2}{*}{$\mathbf{c}_{1}$} & Estratégica $^{2}$ \\
\hline & & Pragmática $^{2}$ \\
\hline
\end{tabular}

Legenda:

1 Subcategorias dedutivas

${ }^{2}$ Subcategorias dedutivas com congruência semântica

3 Subcategorias indutivas

Fonte: Elaborado pelos autores. 


\section{MAPA CONCEITUAL CONSOLIDADO}

A análise de conteúdo, realizada com suporte do software Atlas TI, teve como resultado um mapa conceitual. O uso do mapa conceitual possibilita observar as relações entre as subcategorias de análise, além da interação entre subcategorias dedutivas e indutivas, ilustrando a dinâmica entre o discurso dos entrevistados e a literatura.

A Figura 1 é o mapa conceitual consolidado das dez entrevistas em profundidade realizadas. As subcategorias em negrito foram destacadas pela relevância semântica, enquanto as subcategorias em itálico emergiram da análise de conteúdo. Os números que as acompanham são a contagem absoluta de incidência de cada subcategoria nas entrevistas.

A categoria de análise Visão Empresarial apresentou concentração de referências ao longo das entrevistas na visão estratégica. A subcategoria Visão Estratégica é a mais pertinente entre todas as entrevistas, dada a sua predominância na maneira como os escritórios enxergam a internacionalização.

A categoria Motivações não apresentou uma subcategoria predominante. As subcategorias Tecnologia e Dirigentes se mostraram menos relevantes, enquanto a relação entre o Ambiente Interno e Externo foi considerada importante. Já a inserção do Status diferenciado no mercado interno pela internacionalização é a subcategoria mais relevante.

A subcategoria Status, após análise de concorrência, está associada ao Ambiente Interno e Externo, ou seja, a conquista de um status privilegiado por parte do escritório se dá diretamente pela interação do escritório entre o ambiente interno e externo.

A categoria Barreiras teve apenas uma subcategoria em destaque. As barreiras Não Tarifárias foram recorrentes, com destaque para o conhecimento de mercado, a concorrência local e a língua. Já o Risco de internacionalizar o escritório e a Baixa Profissionalização também se mostraram importantes.

A subcategoria Baixa Profissionalização possui coocorrência com a subcategoria Built by Brazil. Tal relação demonstra que os escritórios, ao serem conscientes da sua baixa profissionalização, buscam no projeto um suporte de capacitação. 
CONSTRUÇÃO DE POLÍTICAS PARA MELHORIA DO PROCESSO DE

INTERNACIONALIZAÇÃO DA ARQUITETURA NO BRASIL: caso Apex-Brasil

A categoria Facilitadores, além da concentração na subcategoria Built by Brazil, destaca a subcategoria Clientes. Os Clientes, de acordo com análise de coocorrência, possuem relação com as subcategorias de Exportação e Contratual. Tal interação ocorre porque os escritórios de arquitetura detectam oportunidades de internacionalização em parceria a partir de clientes já estabelecidos.

$\mathrm{Na}$ categoria Estratégia, a estratégia Contratual possui maior destaque, assim como a Exportação também é considerada relevante. O Investimento Direto, apesar de ter sido uma estratégia adotada por dois escritórios entrevistados, é considerado uma etapa com alto risco e comprometimento financeiro, motivos que incentivam a busca pelas alternativas supracitadas.

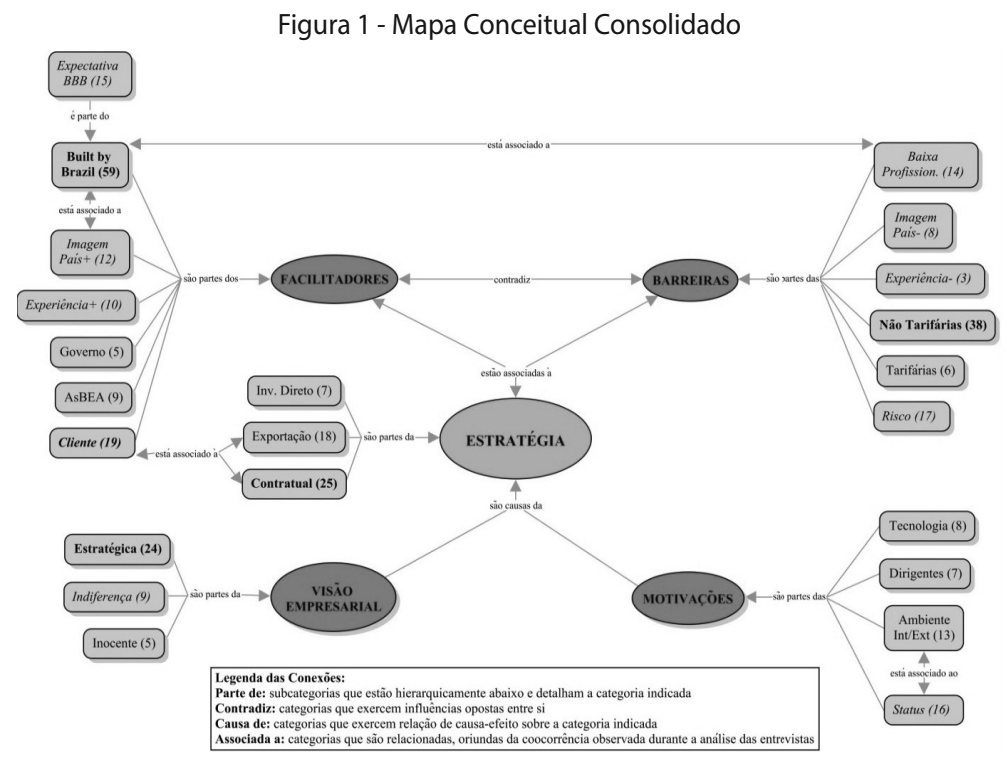

Fonte: Elaborado pelos autores.

É possível traçar um perfil médio entre os entrevistados, onde há visão estratégica sobre o processo de internacionalização, principalmente no que tange ao cálculo de riscos e benefícios. O fechamento de contratos de internacionalização com clientes já estabelecidos se mostrou a melhor maneira de romper as barreiras. Já as barreiras não tarifárias e o risco do processo de internacionalização são as mais relevantes. Porém, não foi possível identificar motiva- 
ções específicas para a internacionalização, sendo elas difundidas entre as subcategorias.

\section{ANÁLISE COMPARATIVA}

Com a comparação entre escritórios ativos, inativos e os órgãos, foram identificadas 14 diferenças, além de possibilitar a análise da visão dos órgãos responsáveis em relação a cada diferença, resumidas no Quadro 4.

A Baixa Profissionalização é uma diferença relevante porque os escritórios ativos reconhecem abertamente que são pouco profissionalizados na internacionalização e que necessitam de investimentos em profissionalização (como cursos e workshops). Os investimentos são uma das principais expectativas sobre o projeto Built by Brazil. De acordo com os órgãos, tais ações são uma das prioridades em curto prazo, mostrando a convergência de visões.

Quadro 4 - Comparação das Entrevistas

\begin{tabular}{|c|c|c|c|}
\hline$\#$ & Escritório & Categoria & Órgãos \\
\hline 1 & \multirow{9}{*}{ Ativos } & Baixa Profissionalização & Convergente \\
\hline 2 & & Cliente & Divergente \\
\hline 3 & & Estratégica & Divergente \\
\hline 4 & & Exportação & Convergente \\
\hline 5 & & Imagem País - & Divergente \\
\hline 6 & & Imagem País + & Convergente \\
\hline 7 & & Não Tarifárias & Divergente \\
\hline 8 & & Risco & Divergente \\
\hline 9 & & Status & Divergente \\
\hline 10 & \multirow{5}{*}{ Inativos } & Built by Brazil & - \\
\hline 11 & & Expectativa BBB & - \\
\hline 12 & & Contratual & Convergente \\
\hline 13 & & Inocente & Convergente \\
\hline 14 & & Tarifárias & Divergente \\
\hline
\end{tabular}

Fonte: Elaborado pelos autores.

Sobre os Clientes, os entrevistados reconhecem de maneira assertiva a sua importância e a influência no desenvolvimento internacional do escritório. Tal importância diz respeito à contratação do escritório para projetos em outros países, porém com o cliente já 
CONSTRUÇÃO DE POLIITICAS PARA MELHORIA DO PROCESSO DE

INTERNACIONALIZAÇÃO DA ARQUITETURA NO BRASIL: caso Apex-Brasil

estabelecido como fio condutor. Os órgãos entrevistados não reconhecem os clientes como relevantes para o processo de internacionalização, havendo assim divergência nas visões.

A Visão Estratégica é um dos aspectos mais relevantes para a compreensão do fenômeno. Há uma clara visão estratégica dos escritórios sobre o seu posicionamento e em relação ao processo de internacionalização. Nos escritórios ativos, a visão estratégica é representada pela superação de barreiras, cálculo de risco e conhecimento de mercado. Já os órgãos possuem uma visão oposta, os considerando inocentes e subestimando seu potencial.

A Exportação foi reconhecida pelos escritórios ativos como uma forma incipiente de internacionalização, principalmente a partir de clientes já conquistados, considerando que muitos possuem empresas multinacionais como clientes. Os órgãos entrevistados convergem com os escritórios ativos, também considerando a exportação como uma estratégia relevante.

A quinta e sexta diferenças, da Imagem País tanto positiva como negativa, possuem dimensões mais complexas que apenas a polarização. Na negativa, os escritórios ativos reconhecem que o Brasil possui uma imagem país negativa e consideram que o projeto Built by Brazil pode realizar ações para melhorar a mesma. Já na positiva, reconhecem que a melhoria da imagem país é relevante para a fluidez da internacionalização, mantendo sua postura de expectativa em relação ao projeto. Os órgãos, por outro lado, convergem apenas na visão da imagem país positiva, porém declararam possuir ações para a melhoria da percepção do Brasil ao redor do mundo.

A sétima e oitava diferenças, as Barreiras Não Tarifárias e o Risco de Internacionalização, são desdobramentos da visão estratégica. As subcategorias mostram que os escritórios ativos possuem conhecimento das barreiras não tarifárias e riscos na internacionalização, e reconhecem como o Built by Brazil é capaz de oferecer suporte. Os órgãos não reconhecem as barreiras não tarifárias e os riscos como impeditivos na internacionalização dos escritórios, divergência que limita a elaboração de ações do projeto.

O Status dos escritórios ativos mostra o impacto da internacionalização no status do escritório, aumento sua competitividade e valor agregado. Tal reconhecimento é relevante por ser um incentivo para os escritórios continuarem a fazer parte do projeto. Os órgãos, 
por outro lado, não reconhecem o status como relevante, sendo a sexta divergência nos nove pontos destacados.

Em relação às subcategorias Built by Brazil e Expectativa dos escritórios em relação ao projeto (Expectativa $\mathrm{BBB}$ ), os escritórios inativos não demonstraram interesse em detalhar o projeto, mostrando desconforto e evitando respostas ao serem questionados diretamente. Não é possível definir uma visão convergente ou divergente em relação aos órgãos, pois a subcategoria diz respeito ao projeto.

Na subcategoria Contratual os escritórios inativos procuram, via de regra, parcerias como uma estratégia de internacionalização. As parcerias são formas eficientes de minimizar o risco e facilitar a internacionalização, minimizando a necessidade das ações do projeto Built by Brazil. Os órgãos são convergentes com os escritórios inativos reconhecendo ser uma das estratégias reincidentes de internacionalização.

A Visão Empresarial Inocente é uma diferença relevante para o entendimento do fenômeno. Em uma relação oposta à visão estratégica dos escritórios ativos, os inativos possuem tendência a uma visão inocente da internacionalização, adotando um papel passivo no processo. Os órgãos consideram que os escritórios, além de serem pouco profissionalizados, não são estratégicos em relação ao processo de internacionalização.

As Barreiras Tarifárias são relevantes para os escritórios inativos. Representadas no discurso pela legislação, tendem a ser intransponíveis se comparadas com barreiras não tarifárias. É possível observar uma desmotivação nos escritórios inativos a se internacionalizarem por conta de tais características; não sendo percebida pelos órgãos entrevistados e representando o último ponto de divergência.

\section{DISCUSSÃO DOS ACHADOS}

A interação entre os resultados da pesquisa e o objetivo do artigo é materializada em nove propostas de ações que são capazes de potencializar a eficácia do projeto. As ações são divididas em três tipos: voltadas para o desenvolvimento interno dos escritórios; voltadas para a competitividade internacional dos escritórios; e voltadas para a promoção da imagem da arquitetura brasileira no mundo.

A primeira ação de desenvolvimento interno é a capacitação dos escritórios no processo de internacionalização. Com base na re- 
CONSTRUÇÃO DE POLÍTICAS PARA MELHORIA DO PROCESSO DE

INTERNACIONALIZAÇÃO DA ARQUITETURA NO BRASIL: caso Apex-Brasil

corrência da categoria de Baixa Profissionalização, uma ação relevante para os escritórios é capacitá-los com aulas magnas, cursos, workshops e acompanhamento no processo de exportação e parcerias, minimizando o risco e maximizando a confiança dos escritórios nas propostas de negócios. A ação engloba categorias como a Baixa Profissionalização, Barreiras Tarifárias e Risco de Internacionalização.

Quadro 5 - Resumo do Conjunto de Propostas de Política

\begin{tabular}{|c|c|c|c|c|c|}
\hline ABORDAGEM & AÇ̃̃̃0 & $\begin{array}{l}\text { CONCEITO } \\
\text { CHAVE }\end{array}$ & $\begin{array}{l}\text { CONCEITO } \\
\text { PRIMÁRIO } \\
\end{array}$ & \multicolumn{2}{|c|}{$\begin{array}{l}\text { CONCEITO(S) } \\
\text { SECUNDÁRIO(S) }\end{array}$} \\
\hline \multirow{3}{*}{$\begin{array}{l}\text { Desenvolvimento } \\
\text { Interno }\end{array}$} & $\begin{array}{l}\text { Capactar os escritórios sobre procedimentitos } \\
\text { espectificos de internacionalização }\end{array}$ & \multirow{3}{*}{$\begin{array}{c}\text { Baixa } \\
\text { profissionalização }{ }^{2}\end{array}$} & Tarifärias ${ }^{1}$ & $\operatorname{Risco}^{2}$ & \\
\hline & $\begin{array}{l}\text { Capactarar os escritórios sobre barreiras } \\
\text { não tarifíarias em mercados alvo especificos }\end{array}$ & & Nào tarifárias ${ }^{1}$ & Risco $^{2}$ & \\
\hline & $\begin{array}{l}\text { Realizar visitas guiadas com escritórios em escritórios } \\
\text { estrangeiros para reconhecimento da estruturara }\end{array}$ & & Nào tarifárias ${ }^{1}$ & Ambiente Int Ext ${ }^{1}$ & Tecnologia/Inovaçãa \\
\hline \multirow{3}{*}{$\begin{array}{c}\text { Competitividade } \\
\text { Internacional }\end{array}$} & $\begin{array}{l}\text { Auxilar os escritórios a captare manter } \\
\text { clientes com potencial intermacional }\end{array}$ & \multirow{3}{*}{ Intermacionalização ${ }^{1}$} & Cliente $^{2}$ & Contratual' & $\operatorname{Risco}^{2}$ \\
\hline & $\begin{array}{l}\text { Organizar rodadas de negócios } \\
\text { com investidores em potencial }\end{array}$ & & Risco $^{2}$ & Exportação ${ }^{1}$ & \\
\hline & $\begin{array}{l}\text { Acompanhar e auxiliar os escritórios } \\
\text { nas etapas de internacionalização }\end{array}$ & & Experiência - $^{2}$ & Risco $^{2}$ & Baixa profissionalização ${ }^{2}$ \\
\hline \multirow{3}{*}{$\begin{array}{l}\text { Promoção de } \\
\text { Imagem }\end{array}$} & $\begin{array}{l}\text { Auxillar na participação dos escritórios } \\
\text { em feriras e concursos internacionais }\end{array}$ & \multirow{3}{*}{ Imagem Pás ${ }^{2}$} & Status $^{2}$ & Não tarifárias' & \\
\hline & $\begin{array}{l}\text { Promover a parceria de divulgação de imagem } \\
\text { dos escritórios com escritórios internacionais }\end{array}$ & & Contratual' & Não tarifäríias ${ }^{1}$ & \\
\hline & $\begin{array}{l}\text { Realizar vistas guiadas da midia internacional a marcos } \\
\text { do desenvolvimento da arquitetura brasiliera }\end{array}$ & & Ambiente IntExt' & Imagem Pás - ${ }^{2}$ & Imagem Pás +2 $^{2}$ \\
\hline
\end{tabular}

Conceto derivedo de pesquis apr

Fonte: Elaborado pelos autores.

A segunda ação pode ser dividida em duas etapas. Na primeira etapa, envolve a identificação dos países alvo do projeto. $\mathrm{Na}$ segunda etapa, há necessidade de capacitação dos escritórios sobre os principais aspectos de mercado, legislação e idioma para a internacionalização. A capacitação sobre os aspectos supracitados tem objetivo semelhante à primeira ação: reduzir o risco de internacionalização dos escritórios. A ação engloba categorias como Baixa 
Profissionalização, Barreiras Não Tarifárias e Risco de Internacionalização.

A terceira ação voltada para o desenvolvimento interno foi realizada de maneira pontual pela gestão anterior do projeto. É proposta a realização de visitas guiadas em escritórios de arquitetura estrangeiros que possuem uma marca estabelecida. As visitas objetivam a compreensão da organização, distribuição de competências, adoção tecnológica e postura de negócios. Engloba categorias como Baixa Profissionalização, Barreiras Não Tarifárias, Ambiente Interno e Externo e Tecnologia e Inovação.

Nas ações para a competitividade internacional dos escritórios, a primeira ação busca a mantença e captação de clientes nacionais que possuem potencial para cooperar na internacionalização, como incorporadoras e construtoras. A internacionalização conjunta minimiza o risco da internacionalização, reduz a burocracia e oferece um suporte ao escritório. Engloba categorias como Internacionalização, Cliente, Estratégia Contratual e Risco de Internacionalização.

A segunda ação foi realizada de maneira pontual na gestão anterior e, apesar de não ter resultados significantes, é relevante de acordo com a pesquisa. A organização e execução de rodadas de negócios com investidores internacionais é uma maneira pragmática de contato e criação de novos negócios, porém devem ser organizadas de maneira estruturada e com convergência de interesses entre as partes. A ação engloba categorias como Internacionalização, Risco de Internacionalização e Estratégia de Exportação.

A terceira ação para a competitividade internacional é um desdobramento das ações de desenvolvimento interno dos escritórios. Além da capacitação, há necessidade de suporte contínuo nas diferentes etapas da internacionalização. $\mathrm{O}$ suporte possui impacto potencializado na minimização de choques causados por possíveis fracassos de internacionalização. A ação engloba categorias como Internacionalização, Experiência Negativa, Risco da Internacionalização e Baixa Profissionalização.

Já na abordagem de promoção de imagem, a primeira ação envolve a divulgação de escritórios em feiras da área e concursos internacionais, principalmente no destaque do diferencial competitivo da arquitetura brasileira. A participação em concursos internacionais é a maneira mais eficaz de escritórios brasileiros receberem uma 
CONSTRUÇÃO DE POLIITICAS PARA MELHORIA DO PROCESSO DE

INTERNACIONALIZAÇÃO DA ARQUITETURA NO BRASIL: caso Apex-Brasil

chancela de qualidade perante a comunidade internacional, levando a maior conhecimento de mercado e à captação de clientes. A ação engloba categorias como Imagem País, Status dos Escritórios e Barreiras Não Tarifárias.

A segunda ação diz respeito à imagem dos escritórios brasileiros por meio de acordos de promoção de imagem. A parceria com escritórios internacionais de renome, não exclusivamente para fins financeiros, e sim para a divulgação do diferencial brasileiro no mercado externo, se mostrou relevante na análise de dados. A associação do escritório brasileiro com um arquiteto reconhecido em outro país insere o brasileiro em um patamar de respeito pelo mercado alvo, ampliando seu reconhecimento. A ação engloba categorias como Imagem País, Estratégia Contratual e Barreiras Não Tarifárias.

A terceira ação para promoção de imagem é relacionada com a interação entre o mercado interno e externo. De acordo com a pesquisa de campo, a mídia europeia é relevante para a promoção da arquitetura, motivando uma ação de visita guiada da mídia e investidores por marcos da arquitetura brasileira. Com tais visitas, há reconhecimento do histórico brasileiro na área, elevando o respeito em relação à tradição da arquitetura brasileira. A ação engloba categorias como Ambiente Interno e Externo, Imagem País Negativa e Imagem País Positiva.

O Quadro 5 apresenta de que maneira cada ação dialoga de maneira conceitual (por meio da revisão da literatura) ou empírica (por meio da análise dos dados coletados em campo) com a pesquisa. Cada abordagem das ações possui um conceito-chave na sua elaboração, enquanto cada ação possui um conceito primário em que foi baseada e um (ou mais) conceito secundário que oferece suporte complementar à ação.

\section{CONCLUSÃO}

A pesquisa apresentou nove propostas de ações que visam aumentar a eficácia do Built by Brazil na internacionalização dos escritórios de arquitetura, considerando em primeira instância o reconhecimento das necessidades dos escritórios e suas principais vantagens competitivas para execução das ações.

O resultado da pesquisa mostra que o projeto Built by Brazil possui potencial para direcionamento de ações que estimulem a internacionalização dos escritórios de arquitetura brasileiros. Apesar 
do potencial, todos os entrevistados, apesar de otimistas, reconhecem que há etapas a serem percorridas para que os resultados esperados sejam alcançados.

A pesquisa apresenta três tipos de contribuição em diferentes áreas de atuação. A contribuição teórica versa sobre a articulação e convergência de conceitos de diferentes fontes teóricas (Modos de Entrada e Ambiente Institucional) para a análise do fenômeno pesquisado. Tal convergência confirma a pertinência das teorias para a análise de fenômenos contemporâneos e a validação empírica dos seus conceitos.

A contribuição gerencial, galgada na aplicabilidade prática em organizações, diz respeito ao mapeamento das necessidades, estratégias, barreiras e motivadores dos escritórios de arquitetura materializados no mapa conceitual. Com o mapeamento disponível, há a possibilidade de escritórios, institutos, agências e investidores se conscientizarem sobre os principais aspectos que envolvem a internacionalização do setor.

A contribuição no âmbito de políticas públicas, foco da pesquisa, se dá de maneira clara na discussão dos achados com as propostas de ações. As ações a serem realizadas pelo projeto são convergentes com as necessidades dos escritórios e o contexto em que se encontram. Ao aplicar as ações sugeridas com embasamento científico e empírico, é possível auxiliar de maneira estratégica a sua internacionalização, além de reduzir os riscos inerentes ao processo.

O estudo, porém, apresenta limitações. A primeira limitação é relacionada à quantidade de escritórios entrevistados por conta de recursos de tempo e pertinência à necessidade da pesquisa, sendo uma possibilidade de desenvolvimento futuro a expansão da amostra para validação das categorias e propostas. A segunda limitação é relacionada ao escopo da pesquisa setor de arquitetura e o projeto Built by Brazil, levando a uma abrangência limitada de resultados. Apesar da limitação, a replicação do método e categorias pode ser realizada em outras indústrias.

\section{REFERÊNCIAS}

AGÊNCIA BRASILEIRA DE PROMOÇÃO DE EXPORTAÇÕES E INVESTIMENTOS. Quem somos. Brasília, DF, [2014]. Disponível em:<http://www2.apexbrasil.com.br/sobre>. Acesso em: 20 dez. 2014. 
CONSTRUÇÃO DE POLÍTICAS PARA MELHORIA DO PROCESSO DE

INTERNACIONALIZAÇÃO DA ARQUITETURA NO BRASIL: caso Apex-Brasil

\begin{abstract}
ASSOCIAÇÃO BRASILEIRA DOS ESCRITÓRIOS DE ARQUITETURA. Histórico institucional. São Paulo, [2014]. Disponível em: $<$ http://www.asbea.org.br/escritorios-arquitetura/ institucional/historico-93809-1.asp>. Acesso em: 20 dez. 2014.
\end{abstract}

BUILT BY BRAZIL. Projeto de Internacionalização. São Paulo, [2014]. Disponível em: <http://www.builtbybrazil.com.br/novo/ principaes-acoes.asp >. Acesso em: 23/12/2014.

CAVUSGIL, S.T; KNIGHT, G; RIESENBERGER, J.R. Negócios internacionais: estratégia, gestão e novas realidades. São Paulo: Pearson Prentice Hall, 2010.

COVIELLO, N.; MARTIN, K. Internationalization of service SMEs: an integrated perspective from the engineering consulting sector. Journal of International Marketing, Chicago, v. 7, n. 4, p. 42-66, 1999.

DENZIN, N. K. Strategies of multiple triangulation. In:

The research act: a theoretical introduction to sociological methods. Piscataway, NJ: Transaction Publishers, 1970.

ERRAMILLI, M. K. Entry mode choice in service industries. International Marketing Review, [S. 1.], v. 7, n. 5, p. 50-62, 1990.

FEDERAÇÃO DAS INDÚSTRIAS DO ESTADO DO RIO DE

JANEIRO. Mapeamento da Indústria Criativa no Brasil: estudos para o desenvolvimento do Rio de Janeiro. Rio de Janeiro, 2012.

GARRIDO, I. L. et al. The EXPERF scale and entry strategies: an assessment for export performance in brazilian companies. BASE: Revista de Administração e Contabilidade da Unisinos, São Leopoldo, v. 6, n. 4, p. 312-323, 2013.

JOHANSON, J.; VAHLNE, J. The mechanism of internationalization. International Marketing Review, [S. 1.], v. 7, n. 4, p. 11-24, 1990.

KRIPPENDORFF, K. A dictionary of cybernetics. Norfolk VA: The Annenberg School of Communications, 1986.

NARAYANAN, V. K.; FAHEY, L. The relevance of the institutional underpinnings of Porter's five forces framework to emerging economies: an epistemological analysis. Journal of Management Studies, [S. 1.], v. 42, n. 1, p. 207-223, 2005.

NORTH, D. Institutions, institutional change and economic performance. Cambridge: Cambridge University Press, 1990.

OLIVEIRA, A. C. de. Mercado de trabalho de Arquitetura. IPOG Especialize Revista Online, Goiânia, n. 4, jan. 2013. 
PENG, M. W. Estratégia Global. São Paulo: Thomson Learning, 2008.

et al. The institution-based view as a third leg for a strategy tripod. Academy of Management Perspectives, New York, v. 23, n. 3, p. 63-81, 2009.

PRIEM, R. L.; BUTLER, J E. Is the resource-based “view” a useful perspective for strategic management research? Academy of Management Review, New York, v. 26, n. 1, p. 22-40, 2001.

ROOT, F. R. Entry strategies for international markets. New York: Lexington Books, 1994.

SCOTT, W. R. Institutions and organizations. Thousand Oaks, CA: Sage, 1995.

TANURE, B.; DUARTE, R. G. Gestão internacional. São Paulo: Saraiva, 2006.

UNITED NATIONS CONFERENCE ON TRADE AND

DEVELOPMENT. Creative Economy Report 2010. New York: United Nations, 2010.

UNITED NATIONS. Service Trade Statistics Database. [Statistic]. New York, [2014]. Disponível em: $<$ https://unstats.un.org/unsd/ servicetrade/default.aspx>. Acesso em: 23 dez. 2014.

WORLD BANK. Annual Report. Washington, DC, 1999. 